\title{
INTERACTIONS OF SHORT-TERM AND LONG-TERM INTEREST RATES IN MALAYSIAN DEBT MARKETS: APPLICATION OF ERROR CORRECTION MODEL AND WAVELET ANALYSIS
}

\author{
Abdul Razak Abdul Hadi' ${ }^{*}$, Zalina Zainuddin', Hafezali Iqbal Hussain ${ }^{2}$, \\ and Raja Rehan ${ }^{1}$ \\ ${ }^{1}$ Universiti Kuala Lumpur Business School, Jalan Sultan Ismail, \\ 50250 Kuala Lumpur, Malaysia \\ ${ }^{2}$ Taylor's Business School, Taylor's University, Jalan Taylors, \\ 47500 Subang Jaya, Malaysia \\ *Corresponding author: abdrazak@unikl.edu.my
}

Published online: 20 March 2019

To cite this article: Abdul Hadi, A.R., Zainuddin, Z., Hussain, H.I., and Rehan, R. (2019). Interactions of short-term and long-term interest rates in Malaysian debt markets: Application of error correction model and wavelet analysis. Asian Academy of Management Journal, 24(Supp. 1), 19-31. https://doi.org/10.21315/aamj2019.24.s1.2

To link to this article: https://doi.org/10.21315/aamj2019.24.s1.2

\begin{abstract}
The study examines the key determinant of short- and long-term interest rates within the framework of term structure of interest rate theory. The study employs both error correction model (ECM) and wavelet analysis on these two important economic variables. Using time series data from January 2005 through April 2017, the empirical findings from long-run regression show there is a significant negative relationship between the short-and the long-term interest rates. The two variables are also found to be negatively correlated. More importantly, the statistical results from the ECM at lag 2 reveal that there is a significant long-term relationship between short- and long-term interest rates. Therefore, this empirical finding is in line with the notion of interest rate expectation theory.
\end{abstract}

Keywords: short-term and long-term interest rates, Engle-Granger cointegration test, wavelet analysis, Malaysian money market, interest rate expectation theory

(C) Asian Academy of Management and Penerbit Universiti Sains Malaysia, 2019. This work is licensed under the terms of the Creative Commons Attribution (CC BY) (http://creativecommons. org/licenses/by/4.0/). 


\section{INTRODUCTION}

It is important to acknowledge the fact that even a strong company is still vulnerable to changes in external forces, for instance, the devastating effect of Asian Financial Crisis 1997 on Asian economies. The crisis has caused local interest rate to increase sharply and forced many companies into insolvencies due to their inability to repay short-term debts and loans. The sudden change in the monetary policy (as shown by a sharp increase in the interest rates) detrimentally affect all market players in the economy. This study is pursued with the motivation to find out the connections between short- and long-term interest rates and how they behave in the Malaysian debt markets. Drastic changes in monetary policy by Malaysia central bank during Asian Financial Crisis 1997 exerted tremendous impact on the financial well-being of both small and large companies. Calverley, Hewin, and Grice (2000) conduct a post-crisis study on the effect of financial crisis on the stock market performances in the emerging economies and discover that despite high yields from the bond markets, the sharp recovery in most emerging stock markets is attributed to the continuing interest and confidence of investors in emerging equity markets. This study is narrowed towards several pertinent issues within the monetary policy and term structure of interest rate frameworks.

Hashemzadeh and Taylor (1988) examine the causality between stock prices, money supply, and interest rates. From the Granger-Sims test, they find that a rise in interest rates reduces the present value of future cash flows to be received by the investors. In addition, the causality seems to be mostly running from the interest rates to stock prices. They also disclose that there is a strong empirical linkage between money supply and stock prices and between stock prices and market interest rates. Many studies also find similar results such as Le (2015), Sweis and Sabri (2016), Owusu-Antwi, Banerjee, and Antwi (2017), Forgha, Serge, and Ajong (2018), and Aremu (2018).

Pierson (1968) concludes that monetary policy affects all rates, with greatest effect on short-term rates. Fama and Schwert (1977) found a statistically significant negative relationship between stock returns and future interest rate changes. Based on the high correlation, they suggest the inclusion of stock price movement in the inflation forecasting models. Interestingly, Ghazali (1992) indicates that there is no significant relationship between money market rates movement and common stock returns in Malaysia. However, the directions of response between two variables are inversely related. This evidence explains the theoretical linkage between money market rates and stock market performance. 
Subsequently, the following research questions are studied and analysed: Did the movements of long-term interest rate (Malaysian Government Security Rate, MGSR) affect the level of short-term interest rate (Treasury Bill Rate, TBR) in the money market? What is the causality relationship between MGSR and TBR? Jensen, Johnson, and Mercer (1998) assert that fundamental and technical analyses on stock valuation rely heavily on monetary policy indicator such as federal funds rate and overnight lending rates. An increase in the federal funds rates signals a period of restrictive monetary policy, while a decrease in the federal funds rates implies an expansive monetary policy. Federal funds rate is the interest rate on overnight loan of deposit at the Federal Reserve Bank (US Central Bank). It is a borrowing rate of one commercial from other commercial banks as the borrowing bank fails to meet the Statutory Reserve Requirement set by the Federal Reserve Bank at the end of business day.

\section{DATA AND METHODOLOGY}

\section{Data and Engle-Granger Co-Integration Test}

This study attempts to uncover the theoretical link between short- and long-term interest rates as proxied by 3-month TBR and 20-year MGSR, respectively. The study period spans from January 2005 through April 2017, involving 150 data points. All data are obtained from Bank Negara Malaysia Statistical Bulletin. The movements of these two variables over time are described in Chart 1 and Chart 2, respectively. It is important to note that TBR is a proxy for short-term interest rate in Malaysian money market. In investigating the lead-lag relationship between the two variables, a methodology by Jensen et al. (1998) is replicated. Their study suggests that changes in interest rates (as represented by the US federal funds rates) denote the degree of monetary stringency. Siegal (1994) concludes that most of the fundamental and technical analyses rely heavily on monetary policy indicators such as the federal funds rate and treasury bills.

This study employs Engle-Granger Co-Integration (1987) procedure. This is a time-series econometric technique introduced by Granger and Weiss (1983), and Engle and Granger (1987). Co-integration is an econometric technique for testing the correlation between non-stationary time-series variables. Two variables are considered co-integrated when a linear combination of the two is stationary, even though each variable is non-stationary at level. Usually when $X$ and $Y$ variables are non-stationary, it is expected that a linear combination of two variables would also be non-stationary. However, this notion has been nullified by Engle and Granger (1987). In order to avoid the problem of non-stationarity, it is necessary to make 
use of first (or higher) difference of time-series data. Engle and Granger (1987) advocate that, if there is an equilibrium relationship between such variables, then the disequilibrium error should fluctuate about zero, i.e., the error terms should be stationary. Once this requirement is fulfilled, $X$ and $Y$ variables are said to be cointegrated. In investigating the relationship between MGSR and TBR, the study assumes one causal direction: MGSR influences TBR since the expectation theory states that long-term interest rates hold a forecast for short-term interest rates in the future.

The study begins with the standard co-integration procedure via error correction model (ECM) to address the pertinent issues. Then, a wavelet analysis is deployed to check the robustness of the results (for details, see Masih \& Masih, 2001). For the wavelet analysis, this study only approves the fundamental methods which are relevant to the research framework. For a more complete and comprehensive development of the theory and the use of wavelets, see Percival (1995), Percival, Walden, and Burnell (2000), Gencay, Selcuk, and Whitcher (2002), and Nguyen and $\mathrm{He}(2015)$.

\section{Wavelet Cross-Correlation}

Literature suggests that Discrete Wavelet Transform (DWT) and Maximal Overlap Discrete Wavelet Transform (MODWT) can decompose the sample variance of a time series on a scale-by-scale basis via its squared wavelet coefficients. However, the MODWT-based estimator has been shown to be superior to the DWT-based estimator (Percival, 1995; Gallegati, 2008). As such, this study applies the MODWT-based estimator. Whitcher, Guttorp, and Percival (2000) extend the notion of wavelet variance for MODWT and introduce the definition of wavelet covariance and wavelet correlation between the two processes, along with their estimators and approximate confidence intervals. To determine the magnitude of the association between two series of observed $X$ and $Y$ on a scale-by-scale basis, the notion of wavelet covariance is used. Following the method used by Gencay et al. (2002) and Gallegati (2008), the wavelet covariance at wavelet scale $j$ may be defined as the covariance between scale $j$ wavelet coefficients of $X$ and $Y$, that is, $\gamma_{X Y, j}=\operatorname{Cov} \tilde{\omega}_{j, t}^{X} \tilde{\omega}_{j, t}^{Y}$. An unbiased estimator of the wavelet covariance using MODWT is given by the following equation after removing all wavelet coefficients affected by boundary conditions (Gallegati, 2008):

$$
\tilde{\gamma}_{X Y, j}=\frac{1}{\tilde{N}_{j}} N-1 \sum_{t=L_{j-1}}^{N-1} \tilde{\omega}_{j, t}^{X} \tilde{\omega}_{j, t}^{Y}
$$


Then, the MODWT estimator of the wavelet cross-correlation coefficients for scale $j$ and lag $\tau$ is estimated by making use of the wavelet cross-covariance, $\tilde{\gamma}_{\tau, X Y, j}$, and the square root of their wavelet variances $\tilde{\sigma}_{X, j}$ and $\tilde{\sigma}_{Y, j}$ are expressed as follows:

$$
\tilde{\rho}_{\tau, X Y, j}=\frac{\gamma_{\tau, X Y, j}}{\tilde{\sigma}_{X, j} \tilde{\sigma}_{Y, j}}
$$

The wavelet cross-correlation coefficient $\tilde{\rho}_{\tau, X Y, j}$, is similar to other usual unconditional cross-correlation coefficients (between 0 and 1) and offers the leadlag relationships between the two processes on a scale-by-scale basis. Starting from spectrum $S_{\omega X, j}$ of scale $j$ wavelet coefficients, it is possible to determine the asymptotic variance $V_{j}$ of the MODWT-based estimator of the wavelet variance. A random interval which forms a $100(1-2 p) \%$ confidence interval is constructed. The formulas to estimate $100(1-2 \mathrm{p}) \%$ confidence intervals and MODWT estimator for $\tilde{v}_{X, j}^{2}$ are provided by Gençay et al. (2002) and Gallegati (2008). Empirical evidence from the wavelet variance suggests that $\mathrm{N}_{j}=128$ is large enough for a good time series model estimation (Whitcher et al., 2000; Gallegati, 2008).

\section{ESTIMATED MODEL}

The estimated model is based on the interest rate expectation theory and specifically formulated as follows:

$$
T B R_{t}=\beta 0+\beta 1 M G S R_{t}+\varepsilon_{t}
$$

where, MGSR $=$ Malaysian Government Securities Rate $\mathrm{TBR}=3$-month Treasury Bill Rate $\varepsilon_{t}=$ error terms

The movements of short- and long-term interest rates are presented in Figure 1. It is evident that the short-term interest rates as proxied by 3-month TBR is more volatile than the 20-year MGSR securities bond yield. It is not certain as to whether the erratic movements in the short-term interest rates are more likely the results of money market sentiments or rather the intervention of Malaysian Central Bank in the monetary systems. 


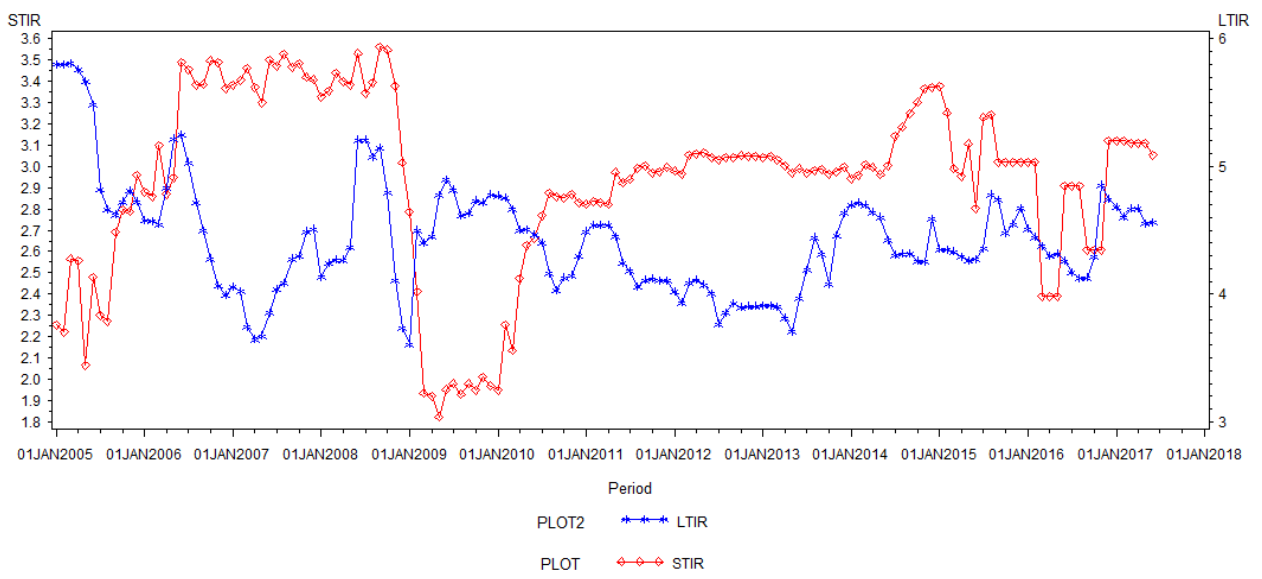

Figure 1. Movements of short- and long-term interest rates

\section{EMPIRICAL FINDINGS}

Figure 2 demonstrates movements in monthly percentage change involving both short- and long-term interest rates. It is worth noting the pattern in their monthly changes and it appears that they move in the opposite direction most of the times. Based upon the standard deviations in Table 1, the short-term interest rate seems more volatile than the long-term interest rate.

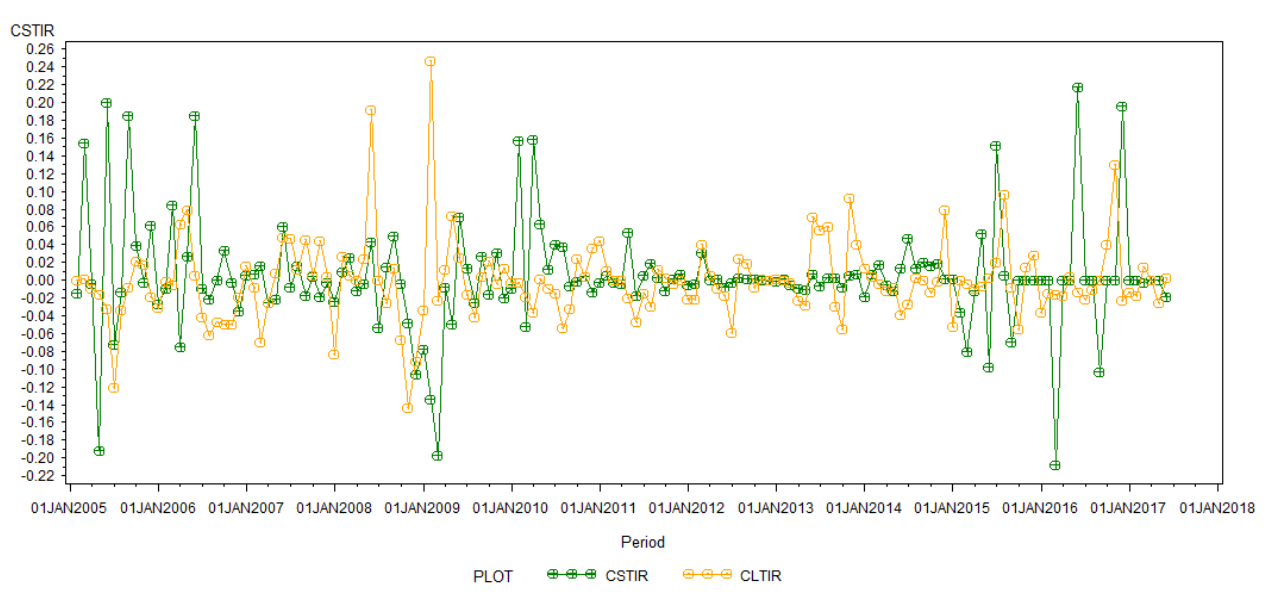

Figure 2. Percentage change in short- and long-term interest rates 
Table 1

Descriptive statistics and correlation analysis: MGSR and TBR

\begin{tabular}{llccccc}
\hline Variable & Label & N & Mean & Std. Dev. & Minimum & Maximum \\
\hline TBR & STIR & 150 & 2.9326733 & 0.4205368 & 1.8230000 & 3.5620000 \\
MGSR & LTIR & 150 & 4.4332133 & 0.4349843 & 3.6080000 & 5.8080000 \\
CSTIR & \% change STIR & 149 & 0.0038779 & 0.0612698 & -0.2082781 & 0.2174822 \\
CLTIR & \% change LTIR & 149 & -0.000622644 & 0.0454452 & -0.1433931 & 0.2472284 \\
\hline
\end{tabular}

Note $:$ TBR = Treasury Bill Rate; MGSR = Malaysian Government Securities Rate; STIR = short-term interest rate; $\mathrm{LTIR}=$ long-term interest rate

To examine the data stationarity, a unit root test by Augmented Dickey-Fuller (ADF) is used and the results are summarised in Tables 2 and 3. Table 2 shows the results from the unit root test performed on MGSR and TBR at level. A hypothesis testing is carried out to determine the significance level of the stationarity test. P-values are reported, indicating the level of significance. The test statistics presented in Table 2 clearly show with all five different values of lags; it is noticeable that both variables are non-stationary at all lags. On the other hand, Table 3 shows the firstdifferenced MGSR and TBR series are stationary respectively, implying that they are integrated at first difference.

Table 2

Stationarity test for MGSR and TBR via ADF (at level)

\begin{tabular}{lccccc}
\hline Type & Lags & Tau (MGSR) & $\operatorname{Pr}<$ Tau & Tau (TBR) & $\operatorname{Pr}<$ Tau \\
\hline Zero mean & 1 & 0.0437 & 0.6917 & -0.81 & 0.3634 \\
& 3 & -0.0902 & 0.6612 & -0.81 & 0.3634 \\
& 5 & 0.0065 & 0.6831 & -0.76 & 0.3865 \\
\hline
\end{tabular}

Note: $\mathrm{H}_{0}=$ Data series have a unit root (non-stationary); $\mathrm{H}_{1}=$ Data series have no unit root (stationary)

Table 3

Stationarity test for first-differenced MGSR and TBR via ADF

\begin{tabular}{lccccc}
\hline Type & Lags & Tau (MGSR) & $\operatorname{Pr}<$ Tau & Tau (TBR) & $\operatorname{Pr}<$ Tau \\
\hline Zero mean & 1 & -8.84 & $<0.0001$ & -8.62 & $<0.0001$ \\
& 3 & -6.08 & $<0.0001$ & -6.80 & $<0.0001$ \\
& 5 & -4.03 & $<0.0001$ & -7.28 & $<0.0001$ \\
\hline
\end{tabular}

Note: $\mathrm{H}_{0}=$ Data series have a unit root (non-stationary); $\mathrm{H}_{1}=$ Data series have no unit root (stationary) 
The test results from long-run regression in Table 4 indicate an acceptance of alternative hypothesis, suggesting that there is a significant negative relationship between MGSR and TBR. For the TBR estimation to be statistically valid, Engle and Granger (1987) suggest that the error terms must be time-invariant, that is, stationary. For this reason, the test for error terms stationarity is warranted. The results from Dickey Fuller and ADF tests presented in Table 5 show that residual (r) is stationary at lag 0 and higher. This implies two important findings. First, there is a significant long-term relationship between MGSR and TBR. Secondly, given the error terms are stationary, both tested variables are said to be co-integrated. As such, the ECM is prepared for further analysis.

Table 4

Test for MGSR and TBR relationship (TBR = dependent variable)

\begin{tabular}{lcccccc}
\hline \multicolumn{7}{c}{ Parameter estimates (long-run regression) } \\
\hline Variable & Label & DF & Parameter estimate & Standard error & $t$-value & $\operatorname{Pr}>|t|$ \\
\hline Intercept & Intercept & 1 & 4.38386 & 0.33308 & 13.16 & $<0.0001$ \\
LTIR & LTIR & 1 & -0.32734 & 0.07478 & -4.38 & $<0.0001$ \\
\hline
\end{tabular}

Note: $\mathrm{H}_{0}$ : There is no long-term relationship between MGSR and TBR; $\mathrm{H}_{1}$ : There is a long-term relationship between MGSR and TBR.

Table 5

Stationarity test for residuals ( $r$ ) via $A D F$

\begin{tabular}{lccccc}
\hline Type & Lags & Rho & $\operatorname{Pr}<$ Rho & Tau & $\operatorname{Pr}<$ Tau \\
\hline Zero mean & 0 & -22.5391 & 0.0006 & -3.84 & 0.0002 \\
& 1 & -39.5077 & $<0.0001$ & -4.79 & $<0.0001$ \\
\hline
\end{tabular}

Note: $\mathrm{H}_{0}$ : Residuals have a unit root (non-stationary); $\mathrm{H}_{1}$ : Residuals have no unit root (stationary)

\section{Error Correction Model (ECM)}

ECM is used to investigate the short- and long-term responses between two nonstationary variables. From the regression results, the optimum lag-length for the ECM lies at lag 2. The details are presented in Table 6.

The $L r$ represents the long-run causality between long-term interest rate (MGSR) and short-term interest rate (TBR). The $p$-value of 0.0001 indicates a significant long-term relationship between the two tested variables. The speed of adjustment of $18.61 \%$ shows how fast a dependent variable returns to its equilibrium. This co-integration technique requires the $p$-value to be divided by two because ECM is based upon the premise of one-tail residuals distribution. The presence of 
long-term relationship between MGSR and TBR also implies a probable shortterm relationship between them. To examine, Granger causality test is performed, and its test statistic is reported in Table 7. The F-value of 1.18 indicates that the null hypothesis cannot be rejected. This suggests absence of short-run causality running from MGSR to TBR. To ensure that the ordinary least square (OLS) assumptions are intact, diagnostic tests are performed and reported.

Table 6

ECM at lag 2

\begin{tabular}{lcccrcc}
\hline \multicolumn{7}{c}{ Parameter estimates - ECM (2) } \\
\hline Variable & DF & $\begin{array}{c}\text { Parameter } \\
\text { estimate }\end{array}$ & $\begin{array}{c}\text { Standard } \\
\text { error }\end{array}$ & $t$-value & $\operatorname{Pr}>|t|$ & $\begin{array}{c}\text { Variance } \\
\text { inflation }\end{array}$ \\
\hline Intercept & 1 & -0.00860 & 0.01464 & -0.59 & 0.5578 & 0 \\
LdMGSR & 1 & 0.00653 & 0.09331 & 0.07 & 0.9443 & 1.06747 \\
L2dMGSR & 1 & -0.14149 & 0.09284 & -1.52 & 0.1298 & 1.05729 \\
Lr & 1 & -0.18611 & 0.04120 & -4.52 & $<0.0001$ & 1.21435 \\
LdTBR & 1 & 0.29312 & 0.07690 & 3.81 & 0.0002 & 1.07949 \\
L2dTBR & 1 & -0.04340 & 0.07899 & -0.55 & 0.5836 & 1.13653 \\
\hline
\end{tabular}

Note: LdMGSR = Lag1 difference MGSR; L2dMGSR = Lag2 difference MGSR; Lr = Lag1 residual; LdTBR $=$ Lag1 difference TBR; L2dTBR = Lag2 difference TBR

Table 7

Short-term relationship between MGSR and TBR

\begin{tabular}{lcccc}
\hline \multicolumn{5}{c}{ Granger causality test (simultaneous Wald F-test) } \\
\hline Source & DF & Mean square & F-value & Pr $>$ F \\
\hline Numerator & 2 & 0.03691 & 1.18 & 0.3102 \\
Denominator & 141 & 0.03127 & & \\
\hline
\end{tabular}

Note: $\mathrm{H}_{0}$ : Absence of short-term relationship (dynamic relation does not exist); $\mathrm{H}_{1}$ : Presence of short-term relationship (dynamic relation exists)

\section{Moments of Specification Test or White Test}

To see whether the error terms have constant variance, moments of specification test or White test is performed. The test results are shown in Table 8. From the test statistic in the Table 8 , the study fails to reject $\mathrm{H}_{0}$ at $5 \%$ significance level. This indicates that the residuals are homoscedastic or having constant variance. 
Abdul Razak Abdul Hadi et al.

Table 8

Moment of specification test

\begin{tabular}{lcc}
\hline \multicolumn{3}{l}{ Test of first and second moment specification } \\
\hline DF & Chi-Square & $\operatorname{Pr}>$ Chi-Square \\
\hline 20 & 15.32 & 0.7576 \\
\hline
\end{tabular}

Note: $\mathrm{H}_{0}$ : Homoscedastic (constant variance in $\varepsilon \mathrm{t}$ ); $\mathrm{H}_{1}$ : Heteroscedastic (inconstant variance in $\varepsilon \mathrm{t}$ )

\section{Autocorrelation Test}

Autocorrelation test is performed in order to examine whether the residual is independent of one another. The test results in Table 9 suggest that any DurbinWatson value that stands between 1.90 and 2.00 supports the presence of non-serial correlation among the residuals. As such, the null hypothesis cannot be rejected.

Table 9

Autocorrelation test

\begin{tabular}{ll}
\hline Durbin-Watson D & 2.000 \\
\hline $\operatorname{Pr}<$ DW & 0.4614 \\
$\operatorname{Pr}>$ DW & 0.5386 \\
\hline
\end{tabular}

Note: $\mathrm{H}_{0}$ : Absence of autocorrelation among the residuals; $\mathrm{H}_{1}$ : Problem of autocorrelation exists

As shown in Figure 3, the cumulative sum control chart (CUSUM test) indicates parameter (short- and long-run parameters) stability over the sample period. As such, the estimated model is considered intact and credible.

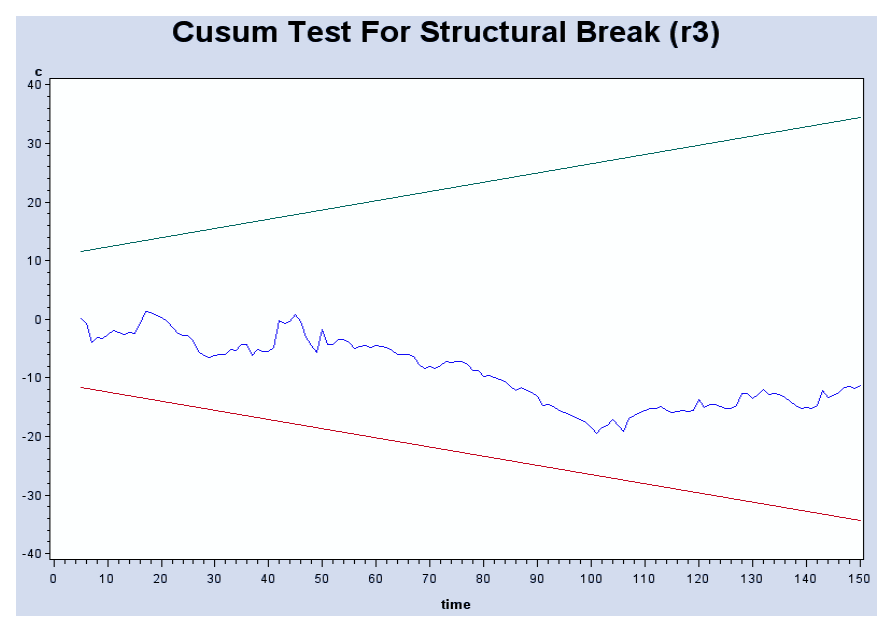

Figure 3. Plot of CUSUM of estimated ECM (2) 


\section{Wavelet Cross-Correlation}

Simple correlations cannot capture the basic fact that lags often exist between variables, whatever their timescales are. To grasp the lead-lag relationship between two variables, we have applied wavelet cross-correlation. As shown Figure 4, even though the data can be decomposed into five scales, the length of period $(\mathrm{n}=150)$ is not enough for the study to come up with the required wavelet statistics. For this reason, the wavelet analysis cannot be pursued.
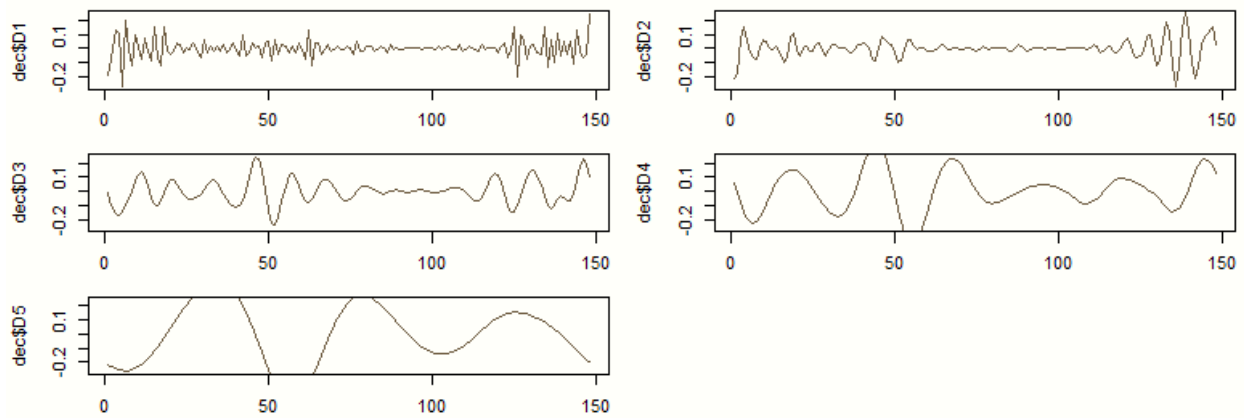

Figure 4. Five scales decomposition process

\section{CONCLUSION}

From the results of long-run regression, there is a statistically significant relationship between short- and long-term interest rates. The empirical results from ECM (2) also support a significant long-term relationship between the two variables coupled with high speed of adjustment. Nevertheless, the statistical results from Granger causality test do not support the dynamic relation between them. It is worth noting that the empirical findings from this study are in line with the notion of interest rate expectation theory, which suggests that movement in short-term interest rate is a function of long-term interest rate. It is hoped that money market and bond market players would understand the nexus of these two important rates in Malaysian monetary system. It is also hoped that corporate managers of public listed companies would understand how these two rates would affect their future capital structure policy. This study still requires a more rigorous analysis, perhaps considering other debt markets in South East Asia so as to increase the sample size and observation period. 


\section{REFERENCES}

Aremu, J.O. (2018). A historical analysis of the nature, causes and impact of the foreign debt Crisis in Latin America, 1970-1980. Humanities and Social Sciences Letters, 6(3), 74-83. https://doi.org/10.18488/journal.73.2018.63.74.83

Calverley, J., Hewin, S., \& K. Grice. (2000). Emerging stock markets after the crisis. Amsterdam: SUERF.

Engle, R.F., \& Granger, C.W.J. (1987). Co-integration and error correction: Representation, estimation and testing. Econometrica, 55(2), 251-276. https:// doi.org/10.2307/1913236

Fama, E.F., \& Schwert, G. (1977). Asset returns and inflation. Journal of Financial Economics, 5(2), 115-146. https://doi.org/10.1016/0304-405X(77)90014-9

Forgha, G., Serge, T., \& Ajong, N. (2018). Effects of lending relationship on the interest rates of commercial banks in Cameroon. Asian Journal of Economic Modelling, 6(2), 208-219. https://doi.org/10.18488/journal.8.2018.62.208.219

Gallegati, M. (2008). Wavelet analysis of stock returns and aggregate economic activity. Computational Statistics \& Data Analysis, 52(6), 3061-3074. https://oi.org/ 10.1016/j.csda.2007.07.019

Gencay, R., Selcuk, F., \& Whitcher, B. (2002). An introduction to wavelets and other filtering methods in finance and economics. Massachusetts, MA: Academic Press.

Ghazali, N.A. (1992). The relationship between the money market rates and the common stock returns: The Malaysia experience. Jurnal Pengurusan, 11(1992), 3-13.

Granger, C.W.J., \& Weiss A.A. (1983). Time series analysis of error-correcting models. In S. Karlin, T. Amemiya, \& L.A. Goodman (Eds.), Studies in econometrics, time series, and multivariate statistics (pp. 255-278). New York, NY: Academic Press. https://doi.org/10.1016/B978-0-12-398750-1.50018-8

Hashemzadeh, N., \& Taylor, P. (1988). Stock prices, money supply and interest rates: The question of causality. Journal of Applied Economics, 20(12), 1603-1611. https://doi.org/10.1080/00036848800000091

Jensen, G.R., Johnson, R.R., \& Mercer, J.M. (1998). The inconsistency of small-firm and value stock premium. Journal of Portfolio Management, 24(2), 27-36. https://doi. org/10.3905/jpm.24.2.27

Le, H.T. (2015). Measuring the stance of monetary policy in Vietnam: A structural VAR analysis. Asian Journal of Economics and Empirical Research, 2(1), 8-22.

Masih, A.M.M., \& Masih, R. (2001). Long and short term dynamic causal transmission amongst international stock markets. Journal of International Money and Finance, 20(4), 563-587. https://doi.org/10.1016/S0261-5606(01)00012-2

Nguyen, T., \& He, T.X. (2015). Wavelet analysis and applications in economics and finance. Research and Reviews: Journal of Statistics and Mathematical Sciences, 1(1), 22-37.

Owusu-Antwi, G., Banerjee, R., \& Antwi, J. (2017). Interest rate spread on bank profitability: The case of Ghanaian banks. Journal of Accounting, Business and Finance Research, 1(1), 34-45. https://doi.org/10.20448/2002.11.34.45

Percival, D.B. (1995). On estimation of the wavelet variance. Biometrika, 82(3), 619-631. https://doi.org/10.1093/biomet/82.3.619 
Percival, D.B., Walden, A.T., \& Burnell, A.C. (2000). Wavelet methods for time series analysis. Cambridge, UK: Cambridge University Press. https://doi.org/10.1017/ CBO9780511841040

Pierson, G. (1968). The effect of economic policy on the term structure of interest rates. Cambridge, MA: Harvard University Press.

Siegal, J.J. (1994). Stock for the long run. New York, NY: McGraw-Hill Education.

Sweis, K.M.H., \& Sabri, T.B.H. (2016). The effect of public debt on domestic product and unemployment: An empirical study on the Palestinian economy. International Journal of Business, Economics and Management, 3(10), 133-143. https://doi. org/10.18488/journal.62/2016.3.10/62.10.133.143

Whitcher, B., Guttorp, P., \& Percival, D.B. (2000). Wavelet analysis of covariance with application to atmospheric time series. Journal of Geophysical Research, 105(D11), 14941-14962. https://doi.org/10.1029/2000JD900110 